\title{
The importance of social values in the prioritization of research: a quantitative example and generalizations
}

\author{
Matt Falcy ${ }^{1}$ \\ ${ }^{1} \mathrm{USGS}$
}

March 26, 2021

\begin{abstract}
1. Identifying critical uncertainties about ecological systems can help prioritize research efforts intended to inform management decisions. However, exclusively focusing on the ecological system neglects the objectives of natural resource managers and the associated social values tied to risks and rewards of actions. 2. I demonstrate how to prioritize research efforts for a harvested population by applying expected value of perfect information (EVPI) analysis to a matrix projection model of steelhead (Oncorhynchus mykiss) and an explicit utility function that models risk/reward objectives. Research priorities identified by EVPI diverge from priorities identified by matrix elasticity analyses that ignore utility. The degree of divergence depends on uncertainty in population vital rates and the particular form of the utility function used to represent risk/reward of harvest. 3. Synthesis and applications. EVPI analysis that includes perceived utility of different outcomes should be used by managers seeking to optimize monitoring and research spending. Collaboration between applied ecologists and social scientists that quantitatively measure peoples' values is needed in many structured decision making processes.
\end{abstract}

Hosted file

Manuscript.pdf available at https://authorea.com/users/404129/articles/515418-theimportance-of-social-values-in-the-prioritization-of-research-a-quantitative-exampleand-generalizations 